DRUG ALERT

\title{
Recommendations pertaining to the use of influenza vaccines and influenza antiviral drugs: Influenza 2015
}

\author{
S Walaza, C Cohen \\ Sibongile Walaza and Cheryl Cohen are medical epidemiologists at the Centre for Respiratory Diseases and Meningitis, National Institute for \\ Communicable Diseases (NICD), Johannesburg, South Africa, and have compiled this article on behalf of the Centre for Respiratory Diseases and \\ Meningitis, NICD and the National Department of Health, Pretoria, South Africa.
}

Corresponding author: S Walaza (sibongilew@nicd.ac.za)

Prevention of influenza is the most effective management strategy. Influenza vaccine is administered each year before the influenza season. Here we provide recommendations for the use of influenza vaccines in anticipation of the 2015 Southern Hemisphere influenza season. For a review of the 2014 influenza season, please refer to the website of the National Institute for Communicable Diseases of the National Health Laboratory Service, www.nicd.ac.za

S Afr Med J 2015;105(2):90-91. DOI:10.7196/SAMJ.9367

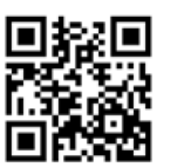

\section{Recommended vaccine} formulation

The following strains have been recommended by the World Health Organization (WHO) for the 2015 Southern Hemisphere influenza season:

- an A/California/7/2009 (H1N1)pdm09-like virus

- an A/Switzerland/9715293/2013 (H3N2)-like virus (A/South Australia/55/2014, A/Norway/466/2014 and A/Stockholm/6/2014 are A/Switzerland/9715293/2013-like viruses)

- a B/Phuket/3073/2013-like virus.

Vaccines should contain $15 \mu \mathrm{g}$ of each haemagglutinin antigen in each $0.5 \mathrm{ml}$ dose.

\section{Indications}

- Pregnant women irrespective of stage of pregnancy, or postpartum (within 2 weeks after delivery)

- Persons (adults or children) who are at high risk for influenza and its complications because of underlying medical conditions and who are receiving regular medical care for conditions such as chronic pulmonary (including tuberculosis) and cardiac diseases, chronic renal diseases, diabetes mellitus and similar metabolic disorders, individuals who are immunosuppressed (including HIV infected persons), and individuals who are morbidly obese (body mass index $\geq 40 \mathrm{~kg} / \mathrm{m}^{2}$ )

- Healthcare workers

- Residents of old-age homes and chronic care and rehabilitation institutions

- Persons aged $>65$ years

- Children aged 6 months - 59 months

- Persons aged 6 months to $\leq 18$ years on long-term aspirin therapy

- Adults and children who are family contacts of high-risk cases

- Any persons wishing to minimise the risk of influenza acquisition, especially in industrial settings, where large-scale absenteeism could cause significant economic losses.

Older people, children aged $<2$ years and severely immunocompromised individuals often have lower protective immune response to trivalent influenza vaccines compared with younger healthy adults. However, even for these people influenza vaccine still provides some protection.

\section{Dosage}

- Adults: Whole or split-product or subunit vaccine: one dose intramuscularly (IM)

- Children (<12 years): Split-product or subunit vaccine: one dose IM

- Children (6 months - 8 years) who have never been vaccinated or when vaccine status is unknown: two doses, 1 month apart

- Children (6 months - 8 years) who have received two or more doses of seasonal influenza vaccine since March 2010 should receive one dose

- Children $<3$ years of age should receive half the adult dose on two occasions separated 1 month apart

- Influenza vaccine is not recommended for infants $<6$ months of age.

\section{Contraindications}

Persons with a history of severe (anaphylactic) hypersensitivity to any components of the vaccine including egg protein, or after previous dose of any influenza vaccine.

\section{Precautions}

- Persons with moderate illness with or without fever should preferably be immunised after symptoms have disappeared.

- History of Guillain-Barré syndrome within 6 weeks of receipt of influenza vaccine.

\section{Timing}

Vaccines should be given sufficiently early to provide protection for the winter. A protective antibody response takes about 2 weeks to develop.

\section{Antiviral chemotherapy}

At present influenza $\mathrm{A}(\mathrm{H} 1 \mathrm{~N} 1) \mathrm{pdm} 09, \mathrm{~A}(\mathrm{H} 3 \mathrm{~N} 2)$ and $\mathrm{B}$ viruses remain sensitive to oseltamivir and zanamivir. A small proportion of $\mathrm{A}(\mathrm{H} 1 \mathrm{~N} 1)$ pdm09 viruses with highly reduced inhibition (HRI) by oseltamivir have been detected globally. High levels of resistance to adamantanes among influenza A viruses have been detected in a number of countries. The use of amantadine and rimantadine in the treatment of 
Table 1. Recommended dosage of antiviral agents for treatment

\begin{tabular}{|c|c|c|c|}
\hline Age group & Weight (kg) & Oseltamivir dosage $^{*}$ & Zanamivir dosage $^{\star}$ \\
\hline Adults & & 75 mg twice per day & $\begin{array}{l}\text { Two } 5 \mathrm{mg} \text { inhalations } \\
\text { (10 mg total) twice per day }\end{array}$ \\
\hline \multicolumn{4}{|l|}{ Premature neonates $^{\dagger}$} \\
\hline$<38$ weeks & & $1 \mathrm{mg} / \mathrm{kg}$ twice per day & \\
\hline 38 - 40 weeks & & $1.5 \mathrm{mg} / \mathrm{kg}$ twice per day & \\
\hline $\begin{array}{l}\text { Infants ( } 14 \text { days - } 12 \\
\text { months) }\end{array}$ & & $3 \mathrm{mg} / \mathrm{kg}$ twice a day & \\
\hline Children & $\begin{array}{l}\leq 15 \mathrm{~kg} \\
>15-23 \mathrm{~kg} \\
>23-40 \mathrm{~kg} \\
>40 \mathrm{~kg}\end{array}$ & $\begin{array}{l}30 \mathrm{mg} \text { twice per day } \\
45 \mathrm{mg} \text { twice per day } \\
60 \mathrm{mg} \text { twice per day } \\
75 \mathrm{mg} \text { twice per day }\end{array}$ & $\begin{array}{l}\text { Two } 5 \mathrm{mg} \text { inhalations } \\
\text { ( } 10 \mathrm{mg} \text { total) twice per day } \\
\text { (only in children aged } \geq 7 \\
\text { years) }\end{array}$ \\
\hline
\end{tabular}

influenza is therefore not recommended. The dosages for treatment with oseltamivir and zanamivir are provided in Table 1.

\section{Antiviral \\ chemoprophylaxis}

Annual influenza vaccine is the best way to prevent influenza, because it can be given described below, for a duration of 7 days, for higher-risk (patients with severe immunosuppression or transplant patients) individuals exposed to influenza instead of the previously recommended long-term lower-dose chemoprophylaxis regimen. These higher-risk individuals need to be carefully monitored during the influenza season for early signs of influenza and should be treated immediately on suspicion of infection.

For a more detailed description of antiviral management and chemoprophylaxis of influenza, please refer to the Healthcare Workers Handbook on influenza on the NICD website http://www.nicd.ac.za/ assets/files/Healthcare $\% 20$ Workers $\% 20$ Handbook\%20on\%20Influenza\%20in\%20 SA\%20_12\%20May\%202014\%281\%29.pdf

For the full report on recommended influenza vaccine, refer to the WHO website http://www.who.int/influenza/ vaccines/virus/recommendations/201409_ recommendation.pdf?ua $=1$

Accepted 9 January 2014 